Review

\title{
Cyclodextrin Derivatives as Chiral Supramolecular Receptors for Enantioselective Sensing
}

\section{Patrick Shahgaldian* and Uwe Pieles}

University of Applied Sciences Northwestern Switzerland, School of Life Sciences, Institute of Chemistry and Bioanalytics, Gründenstrasse 40; 4132 Muttenz, Switzerland

E-mails: patrick.shahgaldian@fhnw.ch, uwe.pieles@fhnw.ch

* Author to whom correspondence should be addressed; E-mail: patrick.shahgaldian@fhnw.ch

Received: 21 March 2006 / Accepted: 13 June 2006 / Published: 22 June 2006

\begin{abstract}
In view of the chiral nature of many bio-molecules (and all bio-macromolecules), most of therapeutically active compounds which target these molecules need to be chiral and "good handed" to be effective. In addition to asymmetric synthetic and separation methodologies, enantioselective chemical sensors, able to distinguish between two enantiomers of the same molecule, are of relevance. In order to design these sensing tools, two major classes of enantioselective layers have been developed. The first is based on molecularly imprinted polymers which are produced (polymerized) in the presence of their target, thus the polymeric material keep in "memory" the size and the shape of this molecule and the system could be used for sensing (not reviewed here). The second approach makes use of sensitive layers containing chiral macrocyclic receptors able of stereoselective molecular recognition; these receptors are mainly based on cyclodextrins. In this contribution, are reviewed achievements in the use of native or chemically modified cyclodextrins for chiral sensing purposes (at interfaces). Potentialities of other chiral macrocycles based on calixarenes, calix-resorcinarenes or crown-ethers as supramolecular receptors for enantioselective sensing are discussed.
\end{abstract}

Keywords: Stereoselective Sensor, Macrocycle, Cyclodextrin, Calixarene, Crown-ether, Supramolecular Chemistry. 


\section{Introduction}

\subsection{General Considerations}

Living organisms are, in one view, compartmented systems where all the components are cooperating with one another through a complex network based on weak force interactions. These forces guarantee the structural and functional integrity of biological systems. They are, for instance, warrants of protein and DNA structures, cell membrane cohesion, cytoskeletal elements activity, etc. These non-covalent bonds include van der Walls forces [1], ionic interactions [2], hydrogen bonds [38] and metal-ligand interactions [9, 10].

“La symétrie c’est l'ennui”*, Victor Hugo said; but nature is not boring...

In fact, many biomolecules and all bio-macromolecules (nucleic acids, proteins, peptides and carbohydrates) are chiral. The term "chirality” was introduced by Lord Kelvin in 1904 for describing molecules which are non superimposable on their mirror images, but the first report concerning asymmetry in chemistry could be attributed to Biot. In the early $19^{\text {th }}$ century, he observed the effect of optically active substances on polarized light (1815). Nevertheless the concept of molecular asymmetry raised with Louis Pasteur who demonstrated in 1848 that sodium ammonium tartrate crystallizes on wine casks during fermentation in two different forms, easily distinguishable under the light microscope and which rotate polarized light with the same magnitude but in opposite directions [11]. More than two decades later (1874), Van't Hoff and Le Bel, working independently on this topic, explained this phenomenon with the theory of the tetrahedral structure of carbon bonds. Coming back to biomolecules, their widespread asymmetry implies that most of molecular interactions in biological systems take place in an asymmetric fashion. Therefore, when scientists aim to design molecules which would interact with biomolecules, they have to consider the asymmetrical structure of the targeted entity [12]. Indeed, in many cases, while one of the enantiomer of a molecule exhibits the desired biological activity (eutomer), the other could show no activity, even toxicity or antagonist effect [13]. For this reason, a US. Food and Drug Agency (FDA) policy statement published in 1992 make the study of pharmacological properties of each enantiomer of a chiral substance mandatory, even if the final commercial product is composed of both enantiomers. Therefore, it seems of a major interest to develop techniques which yield enantiomerically pure compounds. Despite the clear involvement of the pharmaceutical industry in the improvement of asymmetric synthetic methodologies, the straightforward production of optically pure compounds is still laborious and limited. It is consequently of a great interest to develop separation and analytical approaches which could allow the quantification and the separation of chiral compounds. Over the last two decades, a substantial amount of work has been done to develop enantioselective separation tools and the most successful approaches are so far based on high performance liquid chromatography (HPLC) [14-17], capillary electrophoresis (CE) [18-24] and gas chromatography (GC) [25-27]. Even if these techniques are fairly efficient, they are usually time consuming and rather expensive. It seems thus of relevance to develop durable and reliable chiral sensors which allow the quick and inexpensive estimation of the composition of a mixture of enantiomers. The success of these approaches relies on the use of highly efficient chiral selectors, i.e. molecules which have differential affinities for different enantiomers of 
the same molecule. In the range of molecular receptors used for this application, many examples are based on macrocyclic receptors, capable of chiral molecular recognition.

\subsection{Chiral recognition principle}

Chiral recognition is based on the ability of a molecular receptor to form a complex preferentially with one of the enantiomers of a chiral molecule. The higher the difference of affinity of the receptor for these different enantiomers is; the better the chiral discrimination efficiency is. However in contrast to chiral separation experiments, where analytes are subjected to thousands of cumulative adsorptiondesorption events, called theoretical plates; chiral sensing is based on a single theoretical plate. Thus chiral sensing needs much more efficient chiral selectors; and all chiral selectors used in enantioselective separation could not be used for chiral sensing. Except approaches based on molecularly imprinted polymers [28-30], most of receptors used for chiral recognition are based on macrocyclic structures. In a review dealing with enantiomeric recognition of chiral amines [31], Zhang et al. proposed five general rules for effective chiral recognition using macrocyclic receptors, as follows:

- "An essential requirement is that the chiral macrocycles form reasonably stable complexes with the guest enantiomers so that the repulsive interactions can effectively lessen the stability of the complex of one enantiomer.

- Large chiral barrier(s) result in a high degree of enantiomeric recognition.

- Low conformational flexibility of diastereomeric complexes plays an important role in good enantiomeric recognition. Two factors, rigid macrocycles and multipoint interactions, ensure a fixed conformation of the complexes.

- The structural complementarity between chiral macrocycles and enantiomers ensures that the chiral barriers of macrocycles make full use of steric repulsion for enantiomeric recognition.

- Macrocyclic receptors possessing $C_{2}, C_{3}$, and $D_{2}$ symmetry usually show higher enantioselectivity than those of $C_{1}$ and $D_{3}$ symmetry"

These rules, even if established studying supramolecular systems in solution, could also be applied to the design of macrocyclic chiral receptors for interfacial sensing.

\section{3. Scope of the review}

This contribution focuses on the use of cyclodextrins and their derivatives in chiral sensing experiments at solid- liquid and solid-gas interfaces. It emphasizes progress made in this area over the past 20 years, but does not relate chiral recognition and sensing in solution. In a first part, general considerations about cyclodextrins structure and chemistry are given; even if not exhaustive it could help the reader who is novice in the field to understand the use of these macrocycles in chiral recognition. In the second part, a comprehensive inventory of successful sensing experiments at both solid-liquid and solid-gas interfaces is given; information about the cyclodextrin-based chiral selector used and the target analyte are emphasized. In the last part, some examples concerning potential macrocyclic chiral selector based on different macrocyclic skeletons such as calixarenes, calixresorcinarenes and crown-ethers are discussed. 


\section{Cyclodextrins for Chiral Sensing}

\section{1. Generalities}

Cyclodextrins are cyclic oligomers composed of 6, 7 or 8 D-glucopyranosidic units, for $\alpha, \beta$ and $\gamma$ cyclodextrins, respectively [32-34]. They are bound via $\alpha-(1,4)$ glycosydic linkage and are produced by the enzymatic degradation of starch by cyclodextrin glycosyltransferase; a $\alpha$-amylase found in several micro-organisms (Bacillus circulans, Bacillus macerans, Bacillus stearothermophilus, etc.)

The cyclodextrins have been first described by Villiers in 1891[35]. Performing a biodegradation experiment of starch, he isolated $3 \mathrm{~g}$ of a crystalline white substance (from $1 \mathrm{~kg}$ of starch) with a composition he determined to be $\left(\mathrm{C}_{6} \mathrm{H}_{5} \mathrm{O}_{10}\right) \cdot 3 \mathrm{H}_{2} 0$. Villiers found out that this substance resembles to cellulose with regard to its resistance to acidic hydrolysis, but lacking reducing properties of this polysaccharide. These considerations led him to name this substance: “cellulosine”. In the early $20^{\text {th }}$ century, Schärdinger isolated two different dextrins (Villiers' cellulosine) which showed different behaviors with regard to their reaction with iodine, these substances are undoubtedly $\alpha$ and $\beta$ cyclodextrins. The cyclic structure of these dextrins was postulated later (1936) by Freudenberg [36].
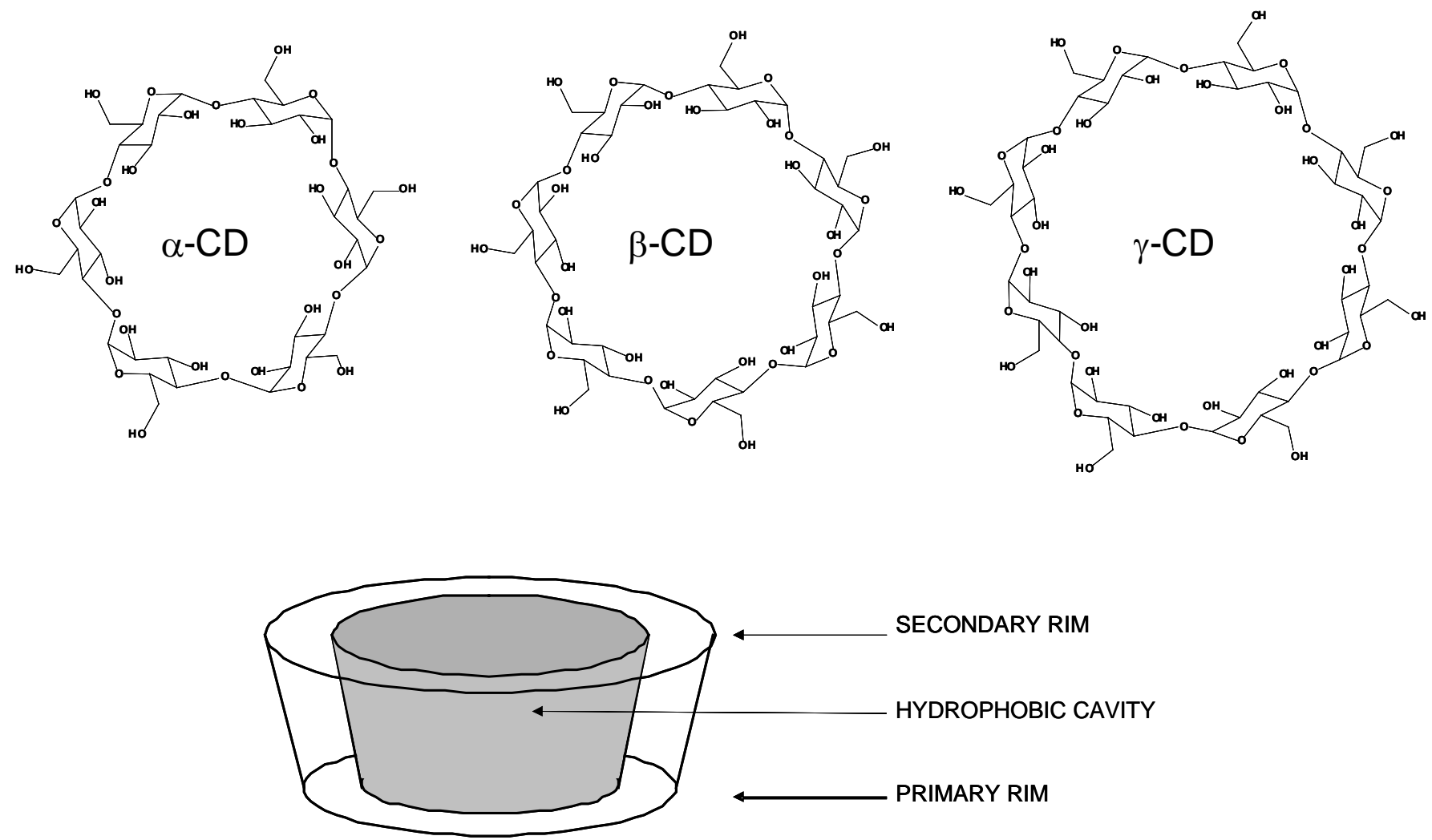

Figure 1. molecular formulae of $\alpha, \beta$ and $\gamma$-cyclodextrins (top view) and schematic representation of the truncated cone shape of cyclodextrins (side view). 
The cyclodextrins present a truncated cone shape (toroidal) structure where primary alcohols are exposed and readily accessible at the primary rim (narrow) and secondary alcohols at the secondary rim (wide) (cf. Figure 1). The three dimensional structures of the cyclodextrins make them attractive because of the differential reactivity of their alcohol functions; which allow regioselective chemical modification either at the primary or at the secondary rim. A systematic analysis of different strategies for regioselective chemical modification of cyclodextrins had been reviewed comprehensively by D’Souza [37]. Important physical properties of cyclodextrins are summarized in Table 1 . The cavity delimited by the cone is highly hydrophobic and present volumes of 174, 262 and $427 \AA^{3}$; for $\alpha, \beta$ and $\gamma$ cyclodextrins respectively. It should be noted that while the internal cavity diameter is increasing with the number of glucosidic units, the height of torus remains constant, equal to $7.9 \AA$. Their water solubility also varies regarding the size of the macrocycle and is explained by differential intramolecular hydrogen-bonding between the hydroxyl groups.

Table 1. important physical properties of cyclodextrins (from ref 32).

\begin{tabular}{lccc}
\hline & Alpha & Beta & Gamma \\
\hline Glucose monomers & 6 & 7 & 8 \\
Molecular weight & 972 & 1135 & 1297 \\
Height of torus, $\AA$ & 7.9 & 7.9 & 7.9 \\
Internal cavity volume, $\AA^{3}$ & 174 & 262 & 427 \\
Internal cavity diameter, $\AA$ & $4.7-5.3$ & $6.0-6.5$ & 8 \\
{$[\alpha]_{\mathrm{D}} 25^{\circ} \mathrm{C}$} & 150 & 162 & 177 \\
Water solubility (g/100mL: $\left.25^{\circ} \mathrm{C}\right)$ & 14.2 & 1.85 & 23.2 \\
Water molecules in cavity & 6 & 11 & 17 \\
\hline
\end{tabular}

The cyclodextrins have been widely used in supramolecular chemistry because of their shape and reactivity. The propensity of native cyclodextrins to form inclusion complexes with organic molecules $[38,39]$ have been extensively studied and explored, not only for academic purposes but also for commercial applications [40]. A broad range of chemical or enzymatic modifications are now well established and broaden significantly the number of application fields of cyclodextrins.

\subsection{Chiral recognition properties of cyclodextrins}

Cyclodextrins are chiral by essence; they are able to form diastereoisomeric complexes with chiral guests. When this complex is of a higher stability for one enantiomer of the guest molecule, it could be considered that enantioselective recognition occurs. The difference of stability between the complex formed with one enantiomer with regard to the other will define the efficiency of this chiral discrimination process. The first example of chiral recognition using cyclodextrins was reported by Cramer and Dietsche; in their original paper the authors described the partial optical resolution of 
mandelic acid using cyclodextrin derivatives [41]. Since then, the use of cyclodextrins for chiral molecular recognition in separation sciences has undergone high growth. Mechanisms of chiral recognition by cyclodextrins have been elucidated and thoroughly reviewed elsewhere [42-44], they could be mainly explained by "three points binding" [45] and "lock and key" rules [46].

\subsection{Cyclodextrins in chiral sensing layer}

Cyclodextrins are chiral host molecules able of chiral discrimination even if they are not chemically modified. Nevertheless, chemical modifications are often needed to improve their physico-chemical properties (i.e. solubility) and also to graft on the macrocyle chemical functions which could allow their covalent anchoring at surfaces. It is important to note that all these chemical modifications have to be done in a way that the chemical functions added do not inhibit the chiral inclusion properties of the macrocyle.

\section{3. 1. Chiral sensing at the solid-liquid interface.}

Cyclodextrins have been used as coating materials of solid surfaces to act as chiral receptors using different sensing methodologies essentially based on potentiometric electrodes but also using surface plamson resonance, cyclic voltametry, resonance Raman (RR) and surface-enhanced resonance Raman spectroscopy (SERRS). In Table 2 are summarized stereoselective sensing experiments where cyclodextrins have been used for their ability of enantiospecific molecular recognition in the liquid phase. It could be seen that for chiral sensing at the "solid-liquid interface", the chiral discrimination properties of the cyclodextrins have been mainly studied by means of potentiometric methods. Parker and coworkers have demonstrated that highly lipophilic $\alpha$-cyclodextrins, per-octylated at both rims, are suitable receptors for chiral sensing of ephedrine, pseudoephedrine and norephedrine in the liquid phase, using potentiometric electrodes (cf. Figure 2) [47, 48]. In these experiments cyclodextrins derivatives have been incorporated into PVC membranes using o-nitrophenyl octyl ether (oNPOE) and bis(butylpenty1) adipate (BBPA) as plasticizers. Compared to many other systems which are very sensitive to ions, it has been demonstrated that this sensor could work in liquids possessing serum salt concentrations of cations $\left(\mathrm{Na}^{+}, \mathrm{K}^{+}, \mathrm{Ca}^{2+}\right)$; which is a major advantage for potential applications of this system. In a further paper, the authors demonstrated that $C$-methyl substituent of ephedrine derivatives, $\beta$ to the aryl ring, act as a stereo-differentiating group, and residual hydroxyl groups on the cyclodextrins are needed for enantiospecificity [49]. These results have also been confirmed by NMR studies. Parker successfully extended his studies to stereoselective sensing of amphetamine derivatives and propanalol; and studied sensing properties of these systems vs. other bio-relevant molecules such as dopamine, acetylcholine, procaine, prilocaine and lignocaine[50]. 
Table 2. stereoselective sensing experiments using native or chemically modified $\alpha-$, $\beta-$ or $\gamma$-cyclodextrins for chiral sensing at the solid-liquid interface using varying sensing methods; $R_{1}, R_{2}$ and $\mathrm{R}_{3}$ are indicated according to the general cyclodextrin formula presented below. [SPR: surface plasmon resonance, $\mathrm{CV}$ : cyclic voltametry]

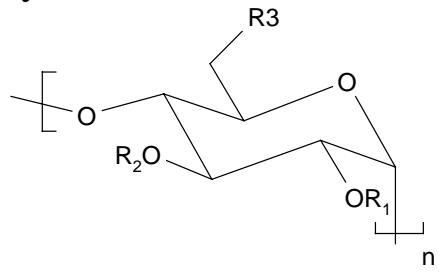

\begin{tabular}{|c|c|c|c|c|c|c|}
\hline Ref & $\mathbf{n}$ & $\mathbf{R}_{\mathbf{1}}$ & $\mathbf{R}_{\mathbf{2}}$ & $\mathbf{R}_{\mathbf{3}}$ & Guest & $\begin{array}{l}\text { Sensing } \\
\text { method }\end{array}$ \\
\hline [47] & 6 & octyl & Octyl, H & O-octyl & ephedrine & Potentiometric \\
\hline [48] & 6 & octyl & octyl & O-octyl & ehedrine & Potentiometric \\
\hline [49] & 6 & $\mathrm{H}, \mathrm{Me}, \mathrm{Ac}$ or Octyl & Octyl & O-octyl & Ephedrinium ion & Potentiometric \\
\hline [50] & & Octyl & $\begin{array}{l}\text { octyl or } \\
\text { dodecyl }\end{array}$ & $\begin{array}{l}\text { O-octyl or } \\
\text { O-dodecyl }\end{array}$ & $\begin{array}{l}\text { amphetamine } \\
\text { propanalol }\end{array}$ & Potentiometric \\
\hline [51] & 7 & trimethylammoniopropyl & $\mathrm{H}$ & $\mathrm{OH}$ & ramipril & Potentiometric \\
\hline [52] & 7 & trimethylammoniopropyl & $\mathrm{H}$ & $\mathrm{OH}$ & $\begin{array}{l}\text { cilazapril } \\
\text { pentopril } \\
\text { trandolapril }\end{array}$ & Potentiometric \\
\hline [53] & $\begin{array}{l}6,7 \\
\text { or } 8\end{array}$ & $\mathrm{H}$ & $\mathrm{H}$ & $\mathrm{OH}$ & perindopril & Potentiometric \\
\hline [54] & 7 & trimethylammoniopropyl & $\mathrm{H}$ & $\mathrm{OH}$ & perindopril & Potentiometric \\
\hline [55] & 7 & trimethylammoniopropyl & $\mathrm{H}$ & $\mathrm{OH}$ & proline & Potentiometric \\
\hline [56] & 7 & $\mathrm{H}$ & $\mathrm{H}$ & $\mathrm{NH}-\mathrm{CO}-\left(\mathrm{CH}_{2}\right)_{n} \mathrm{~S}\left(\mathrm{CH}_{2}\right)-{ }_{n} \mathrm{CH}_{3}$ & thyroxine & SPR \\
\hline [57] & 6 & $\mathrm{H}$ & $\mathrm{H}$ & $\mathrm{NH}\left(\mathrm{CH}_{2}\right)_{2} \mathrm{SH}$ & Phenyl-ethylamine & $\mathrm{CV}$ \\
\hline [58] & 6 & $\mathrm{H}$ & $\mathrm{H}$ & $\mathrm{NH}\left(\mathrm{CH}_{2}\right)_{2} \mathrm{SH}$ & DOPA-derivatives & $\mathrm{CV}$ \\
\hline
\end{tabular}




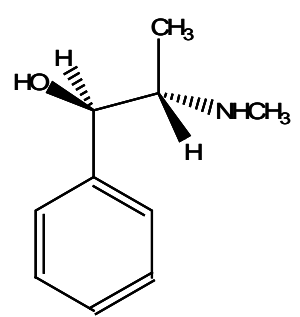

1R, 2S-(-)-ephedrine

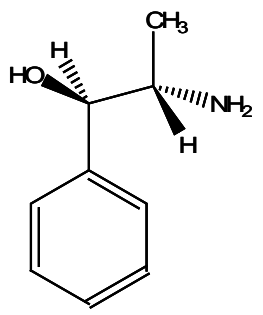

1R, 2S-(-)-norephedrine

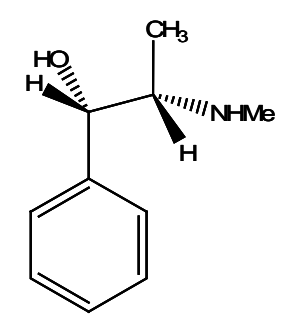

1S, 2R-(+)-ephedrine

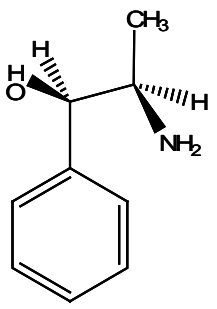

1S, 2R-(+)-norephedrine
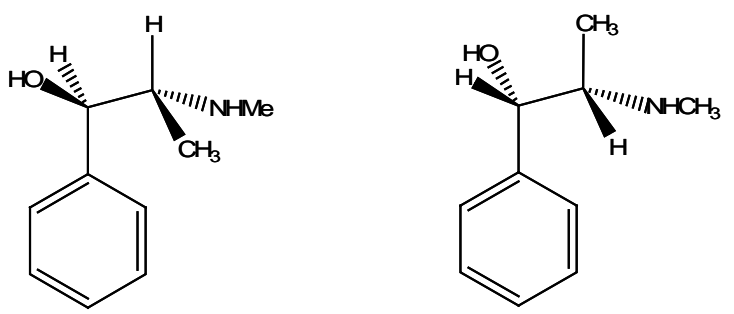

1R, 2R-(-)-pseudoephedrine

1S, 2S-(+)-ephedrine

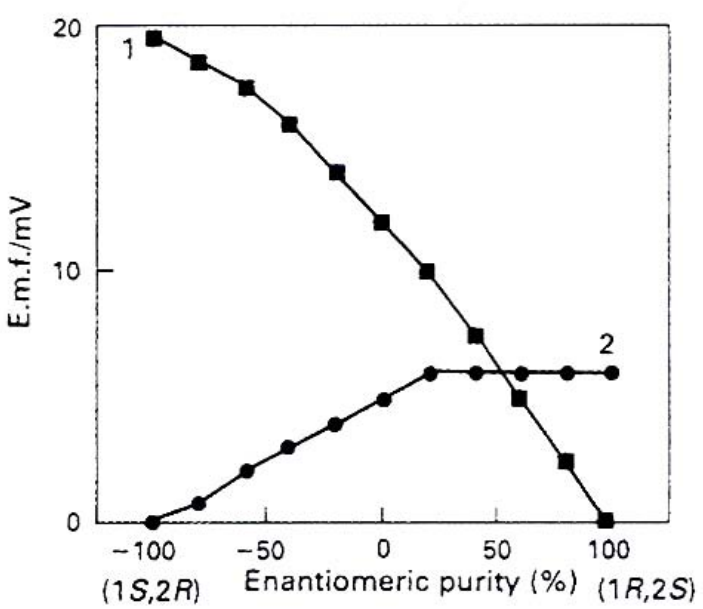

Figure 2. Example of Behaviour of electrodes in solutions of varying enantiomeric composition. Electroactive membrane: $\alpha$-CD-BBPA; inner filling solution: $1.0 \mathrm{mmol} \mathrm{dm}{ }^{-3} \mathrm{NH}_{4} \mathrm{Cl}$; conditioned in 10 mM (+)- or (-)-ephedrine, (-)-ephedrine-BBPA; and 2, (+)-ephedrine-HCl-BBPA. [BPPA: Bis(1butylpentyl) adipate] [reproduced with permission from Analyst 1992, 117, 1313. Copyright 1992, the Royal Society of Chemistry]

Potentiometric electrodes have also been used by Stefan and co-workers to design enantioselective sensors for $S$-ramipril which is an angiotensin converting enzyme (ACE) inhibitor used in high blood pressure treatments. They used membrane electrodes based on graphite paste (graphite powder and paraffin oil) impregnated with 2-hydroxy-3-trimethyl-ammoniopropyl- $\beta$-cyclodextrin (as a chloride salt) [51]. This sensor could be used for enantiopurity tests using $S$-ramipril as raw material or in its pharmaceutical formulations, in the concentration range from $1.80 \times 10^{-5}$ to $2.3 \times 10^{-1} \mathrm{M}$, with a detection limit of $10^{-5} \mathrm{M}$. These electrodes have also been shown to be efficient for enantiopurity studies of S-captopril [59], proline[55], cilazapril, pentopril, trandolapril[52] and perindopril [53, 54]. Molecular formulas of these therapeutically active molecules are given in Figure 3. Stefan and coworkers have also demonstrated that in the case of proline, the $\alpha$-cyclodextrin showed an improved time stability and enantioselectivity with regard to the $\beta$ - and $\gamma$ - derivatives [60]. At this point, it could be noted that all the molecules cited above possess at least one hydrophobic cyclic part, which could presumably be included in the hydrophobic cavity of the cyclodextrin receptor, polar functions of the guest molecule are then in close contact with eventual polar functions of the receptor and then could interact to improve the stability and the enantioselectivity of the complex. 


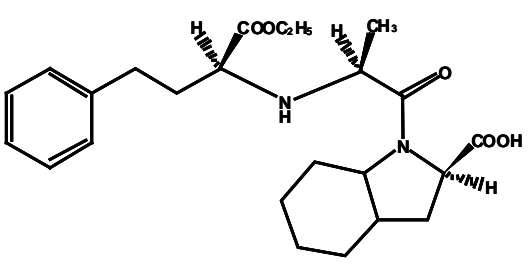

S-ramipril

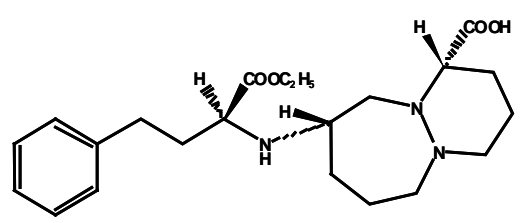

S-cilazapril

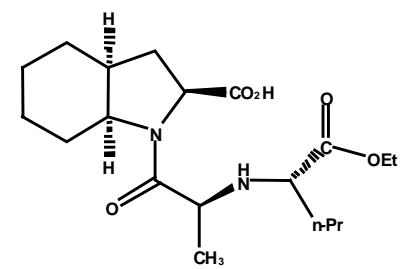

S- perindopril

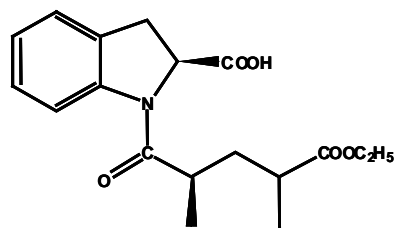

S-pentopril

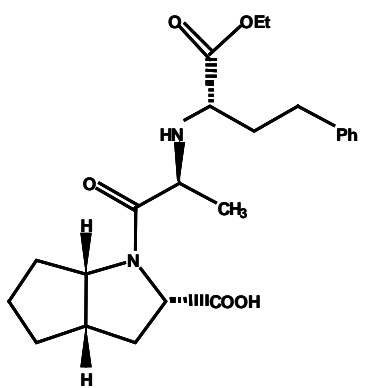

S-trandolapril

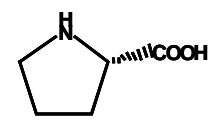

S-proline

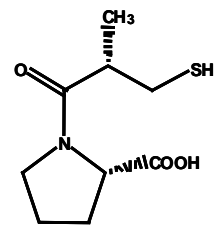

S-captopril

Figure 3. molecular formulas of chiral drugs studied using membrane electrodes based on graphite paste impregnated with 2-hydroxy-3-trimethyl-ammoniopropyl- $\beta$-cyclodextrin.

In addition to potentiometic approaches, enantioselective sensing experiments have also been carried out using surface plasmon resonance and cyclic voltametry. Even if surface plasmon resonance is known as a powerful tool for monitoring biomolecular interactions at the sold-liquid interface, it is much less used for sensing small molecules because of the low sensitivity of commercial systems for low molecular weight molecules (typically $<500$ ). In his extensive work on cyclodextrins, Reinhoudt demonstrated that $\beta$-cyclodextrins, modified on the primary rim with thioether containing hydrocarbon chains, are able to self assemble as monomolecular densely packed layers; these systems have been fully characterized [61]. To our opinion, the most elegant application of these systems is their use for building nanoscale molecular printboards [62]. We used these self-assembled monolayers (SAMs) to build a SPR-based sensor, able to discriminate between enantiomers of thyroxine[56]. In Figure 4 are presented binding sensograms obtained for D- and L-enantiomers of thyroxine, molecular formula and apparent affinity constants for varying proportions of each enantiomer. From these results, it could clearly be seen that cyclodextrin-based SAMs present a better affinity for the D-enantiomer of thyroxine; apparent affinity constants increase linearly with increasing the proportion of the D- 
enantiomer. This system could therefore be considered as a suitable tool for determining enantiomeric compositions of mixtures of D- and L- thyroxine.

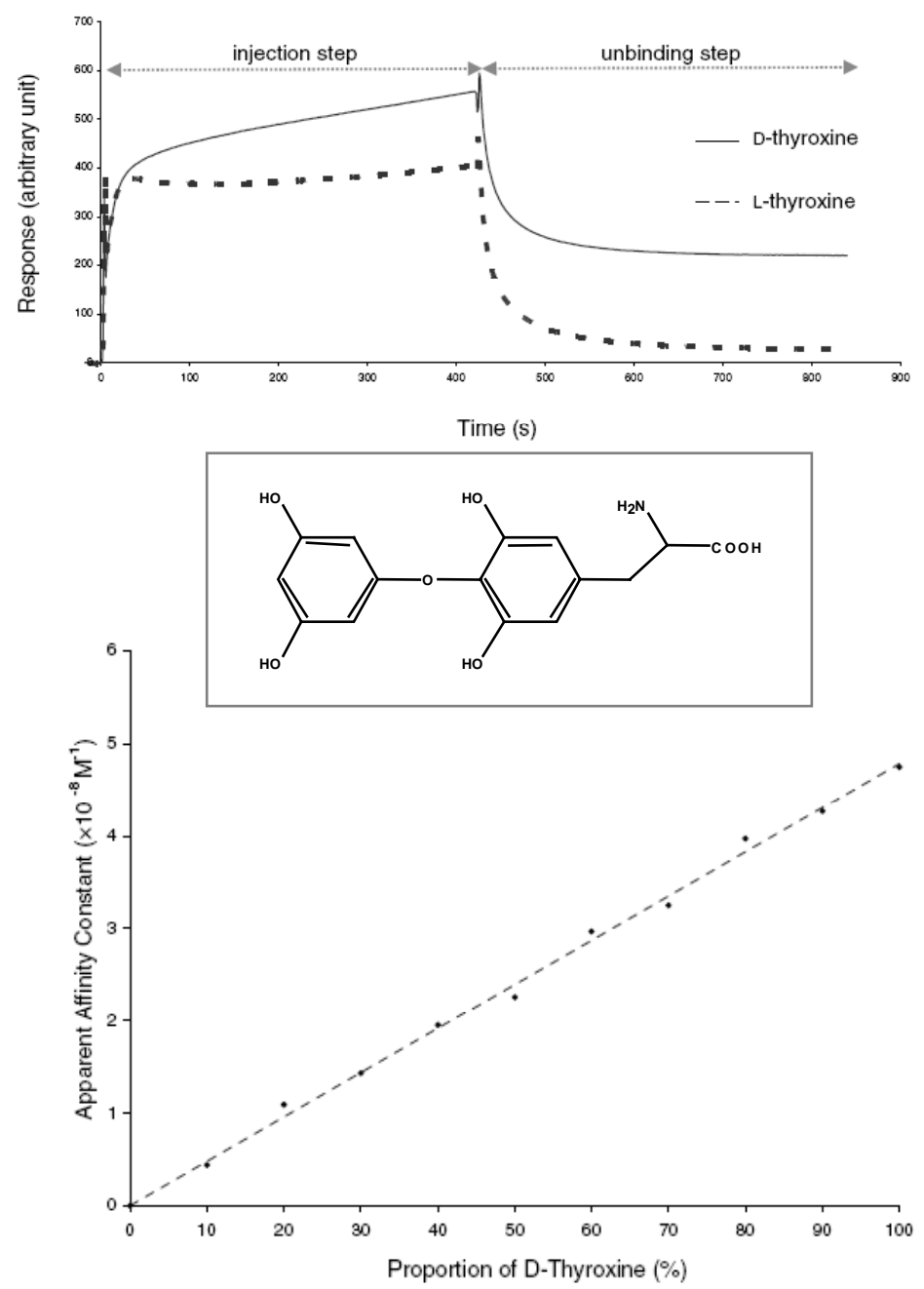

Figure 4. SPR binding sensograms of D- and L-Thyroxine to cyclodextrin based SAM (top), molecular formula of thyroxine (squared) and apparent affinity constant values in function of proportion of Dthyroxine in a mixture of enantiomers. [reproduced with permission from J. Incl. Phenom. Macrocyclic Chem. 2005, 53, 35. Copyright 2005, Springer].

SAMs of cyclodextrin derivatives have also been used as sensitive stereoselective layers in cyclic voltametry experiments. Kitano and co-workers produced cyclodextrins bearing four thiol-containing chains at the primary rim and unmodified on secondary alcohols. These molecules form SAMs on gold surfaces and have been studied by mean of competitive cyclic voltametry, for their ability to interact with 3,4-dihydroxyphenylalanine (DOPA) and its derivatives. In this report, the authors checked SAMs formation and compared cyclic voltamograms of treated surfaces with bare gold. They showed that even if they found some stereospecific recognition effect, it is not high enough to build stereoselective sensor and postulated on the need to rationally modify the secondary rim of cyclodextrins to improve these results[58]. They came to the same conclusion studying specific 
binding of four stereoisomers of azo compounds, o- or $p$-methyl red and (R)-(+)- or (S)-(-)-1phenylethylamine conjugates[57]. They have also investigated this system on silver surfaces using resonance Raman (RR) and surface-enhanced resonance Raman spectroscopy (SERRS)[63]. An illustration of the approach used in these experiments is given in Figure 5.

Figure 5. Oxydo-reduction reaction of DOPA (left) and schematic representation of an inclusion complex of DOPA and cyclodextrin attached to a gold surface; included DOPA is submitted to a redox reaction. [reproduced with permission from Langmuir 1999, 15, 1887. Copyright 1999, the American Chemical Society]

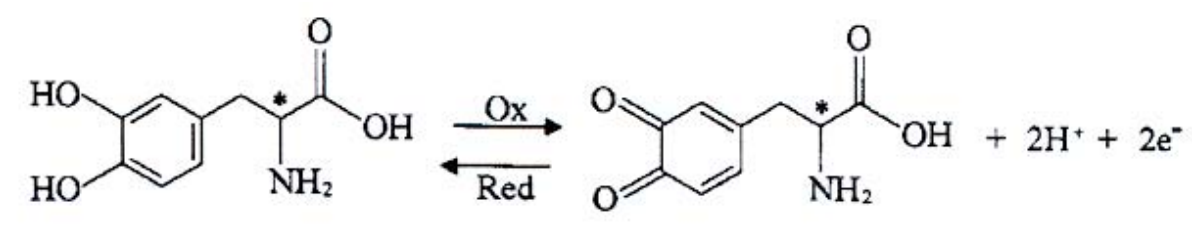

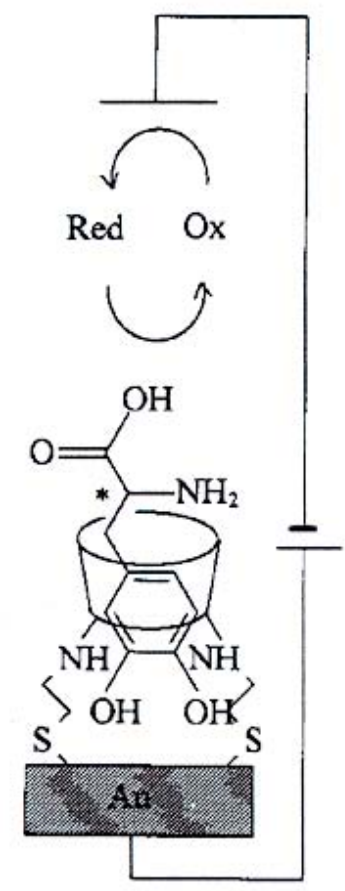

\section{3. 2. In the gas phase}

As mentioned above, the interactions between organic (chiral) guests and cyclodextrins are mainly driven by hydrophobic interactions of the guest entity within the cavity of the macrocycle. In the gas phase, while hydrogen bonding is usually strengthen, hydrophobic effects are drastically weakened [64]. Thus, the use of cyclodextrins is much less adapted for sensing at solid-gas interfaces. Nevertheless, several reports concerning the use of cyclodextrins for chiral sensing of gaseous species have been published, they are summarized in Table 3. It could be seen that quartz crystal microbalance is the most employed tool for monitoring stereospecific interactions at the solid-gas interface. In a few words, quartz crystal microbalance measures mass loading on the sensor chip by measuring the change in the resonant frequency of a piezoelectric quartz crystal and could be used in gaseous or liquid environment. In 1994, Ide et al. reported on the use of per-alkylated $\alpha, \beta$ and $\gamma$ cyclodextrins for sensing aroma components in the gas phase[65]. They showed that for both citronellal and rose oxide, 
the best affinity is observed for the D-enantiomer with a higher sensor response using per-alkylated $\alpha$ cyclodextrin and per-alkylated $\beta$-cyclodextrin, for rose oxide and citronellal respectively. In this study, it is also shown that chiral discrimination does not only depend on the size of the cyclodextrin derivative used but also on its substituent groups.

Table 3. stereoselective sensing experiments using modified $\alpha-\beta-$ or $\gamma$-cyclodextrins for chiral sensing at the solid-gas interface using various sensing methods; $R_{1}, R_{2}$ and $R_{3}$ are indicated according to the general cyclodextrin formula presented below. [QCM: quartz crystal microblalance, SPR : surface plasmon resonance, TSMR : thickness shear mode resonator, SAW : surface acoustic wave sensor]

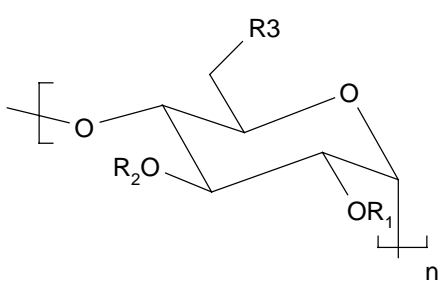

\begin{tabular}{|c|c|c|c|c|c|}
\hline $\mathrm{n}$ & $\mathbf{R}_{1}$ & $\mathbf{R}_{\mathbf{2}}$ & $\mathbf{R}_{\mathbf{3}}$ & Guest & Sensing method \\
\hline $6,7,8$ & $\mathrm{Me}$ & Me, pentyl & O-Me & $\begin{array}{l}\text { citronellal } \\
\text { rose oxide }\end{array}$ & $\mathrm{QCM}$ \\
\hline 7 & $\begin{array}{l}\text { Ethyl, methyl, } \\
\text { acetyl }\end{array}$ & $\begin{array}{l}\text { Ethyl, methyl, } \\
\text { acetyl }\end{array}$ & TBDMS & limonene & $\mathrm{QCM}$ \\
\hline 7,8 & pentyl & pentyl & O-Me & $\begin{array}{l}\text { Pinene } \\
\text { pinane }\end{array}$ & $\mathrm{QCM}$ \\
\hline 7 & $\begin{array}{l}\text { Me, Pentyl, } \\
\varphi \mathrm{CHO}\end{array}$ & $\begin{array}{l}\text { Me, Pentyl, } \\
\varphi \mathrm{CHO}\end{array}$ & $\begin{array}{l}\text { mono- } \\
\text { ONHCONH}\left(\mathrm{CH}_{2}\right)_{n} \mathrm{SH}\end{array}$ & methyl-lactate & $\mathrm{QCM}$ \\
\hline 7 & & & $\begin{array}{l}(\mathrm{OMe})_{6} \\
\mathrm{ONHCONH}\left(\mathrm{CH}_{2}\right)_{n} \mathrm{SH} \\
\mathrm{n}=2,6 \text { or } 11\end{array}$ & $\begin{array}{l}\text { 2-butanol } \\
\text { 2-octanol } \\
\text { methyl-lactate } \\
\text { ethyl-lactate } \\
\text { carvone }\end{array}$ & $\mathrm{QCM}$ \\
\hline 7 & pentyl & Butanoyl & O-pentyl & $\begin{array}{l}\text { Methyl lactate } \\
\text { Methyl chloropropionate }\end{array}$ & SAW \\
\hline 8 & pentyl & butanoyl & O-pentyl & $\begin{array}{l}\text { Sevoflurane degradation } \\
\text { product }\end{array}$ & $\begin{array}{l}\text { TSMR, SAW, } \\
\text { SPR }\end{array}$ \\
\hline 8 & butanoyl & pentyl & O-pentyl & $\begin{array}{l}\text { methyl-lactate } \\
\text { methyl-chloropropionate } \\
\text { flurane derivatives }\end{array}$ & SMR \\
\hline
\end{tabular}

A study reporting on chiral sensing of limonene using a cyclodextrin-based QCM sensor had been published by Fietzek et al. In this paper, it is described that sylilated $\beta$-cyclodextrins introduced in a 
polysiloxane layer, spayed on a QCM chip, could act as enantioselective sensors which exhibit a better affinity for $R$-limonene (cf. Figure 6) [66].

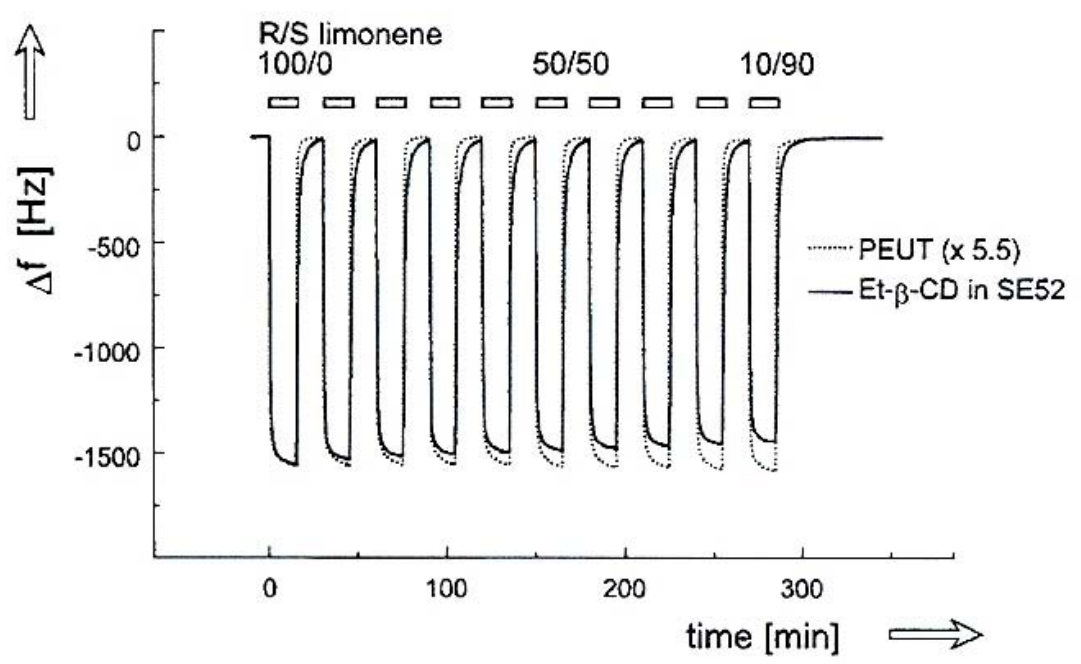

Figure 6. A series of sensor signals for limonene of different enantiomeric composition on a cyclodextrin coated sensor (Et- $\beta$-CD) and an achiral polyetherurethane (PEUT) sensor. The cyclodextrin coated sensor shows a difference of $100 \mathrm{~Hz}$ between R- and S-limonene while there is no differences for the achiral PEUT sensor. [reproduced with permission from Fresenius J. Anal. Chem. 2001, 371, 68. Copyright 2001, Springer Verlag]

Other terpenes such as pinene and pinane have been studied using enantioselecive QCM sensors and compared with gas chromatographic retention data [67]. It is demonstrated that enantiomeric separation was carried out using capillary columns coated with heptakis(6-O-methyl-2,3-di-O-pentyl)$\beta$-CD, octakis(6-Omethyl-2,3-di-O-pentyl)- $\gamma-C D$, and heptakis(2,3,6-tri-Omethyl)- $\beta$-cyclodextrin. Significant separation factors, same elution order than capillary GC with the exception of trans-pinane with octakis(6-O-methyl-2,3-di-O-pentyl)- $\gamma$-CD and $\alpha$-pinene with 2,3,6-tri-O-methyl- $\beta$-CD, are observed. Surface Accoustic wave devices (SAW) and Fourrier transform infrared external reflectance (FT-IR-ERS) spectra were also used to probe chiral recognition in the gas phase. Hierlemann et al. have demonstrated than SAW surfaces, coated with cyclodextrins, present high sensor response when specific molecular recognition occurs, with regard to sensograms obtained when the analyte is ordinary physisorbed on the surface [70]. FT-IR measurements also show drastic changes in the IR spectra. These systems have been shown to react enantioselectively with methyl-chloropropionate and methyl-lactate and support the results obtained using thickness shear mode resonator [72]. Kieser et al. have studied stereoselective interactions of the chiral halodieter 1,1,1,3,3-pentafluoro-2(fluoromethoxy)-3-methoxypropane (halodieter B) using Lipodex E® [71]. Lipodex E is a commercially available polymer made of polysiloxane containing octakis(3-O-butanoyl-2,6-di-O-npentyl)- $\gamma$-cyclodextrin; it is widely used for chiral separation purposes. In this paper, the authors showed, using thickness shear mode resonators (TSMR), surface acoustic wave sensors, surface plasmon resonance (SPR), and reflectometric interference spectroscopy, that this polymer layer could also be used for stereospecific sensing of sevoflurane degradation products. 

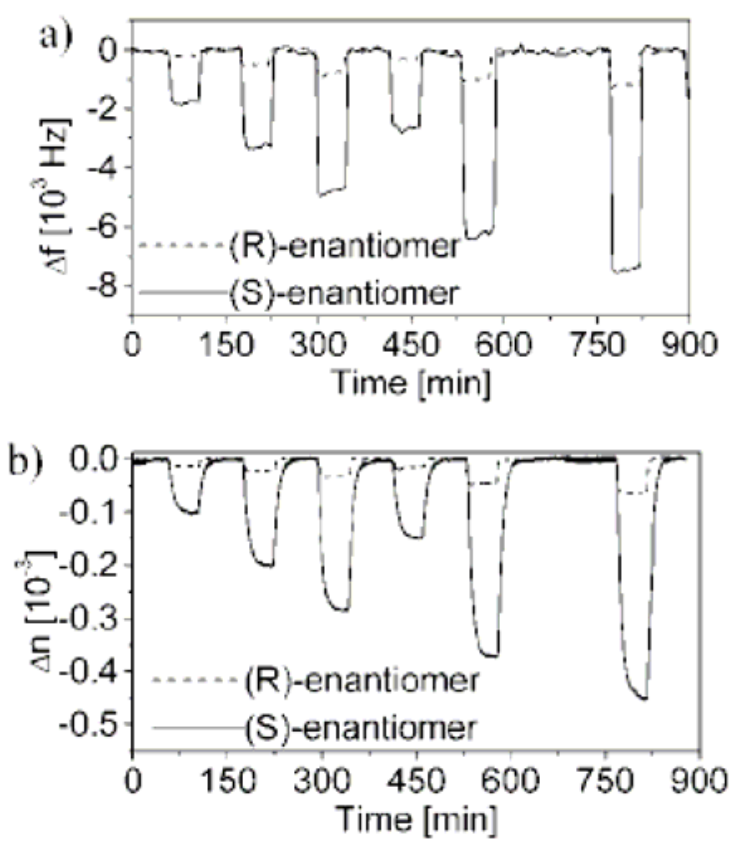

Figure 7. Comparison between SAW (a) signals and SPR (b) signals with Lipodex E as sensor coating on exposure to the single enantiomers of halodiether B. [reproduced with permission from Anal. Chem. 2002, 74, 3005. Copyright 2002, the American Chemical Society].

In the above cited experiments, cyclodextrins were sprayed on the sensor chip but it has also been demonstrated that they can be used as self assembled monolayers when bearing sulphur containing moieties[68, 69]. Monothiolated cyclodextrins (cf. Figure 8) had been produced via a "phosphine imide reaction" [73] and used to form SAMs on gold surfaces. It is demonstrated that these systems are efficient for gas phase chiral sensing of methyl- and ethyl-lactate, 2-butanol, 2-octanol and carvone (cf. Figure 8) .

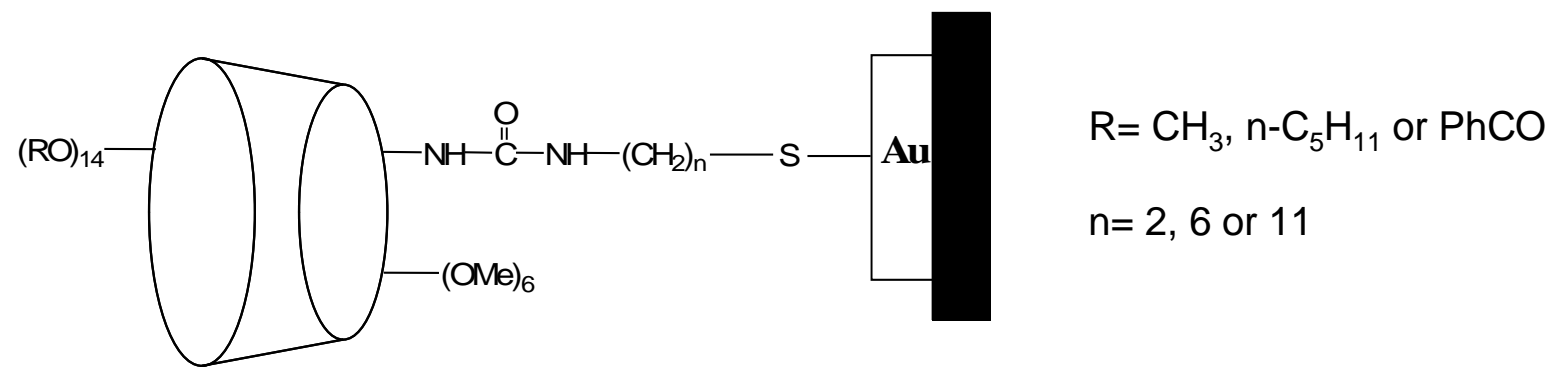

Figure 8. Example of a thiol-bearing cyclodextrin used for enantioselective SAM layer. 
<smiles>CC(C)=C[C]1CC(C)CCO1</smiles>

citronelal<smiles>CCC(=O)C(C)C</smiles>

ethyl-lactate<smiles>CC1=CCC2CC1C2(C)C</smiles>

$\alpha$-pinene

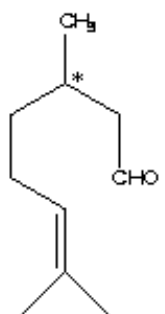

Rose oxide<smiles>C=C(C)C1CC=C(C)C(=O)C1</smiles>

carvone

Methyl-chloropropionate<smiles>COC(=O)C(C)Cl</smiles><smiles>C=C1CCC2CC1C2(C)C</smiles>

$\beta$-pinene<smiles>CC(=O)C1CC=C(C)CC1</smiles><smiles>CC(=O)C(C)C</smiles>

methyl-lactate<smiles>CC1CCC2CC1C2(C)C</smiles>

pinane

Figure 9. molecular formulae of chiral analytes studied in gas phase cyclodextrin-based chiral sensors.

\section{Other chiral macrocycles, potential candidates for chiral sensing}

\subsection{Calixarenes and Calix-resorcinarenes}

Calixarenes are macrocyclic molecules produces by the base catalyzed reaction of para-tert-butylphenol and formaldehyde [74-76]. Most common calix-arenes are composed of 4, 6 or 8 phenolic units, linked by methylene bridges. They have been widely used in supramolecular chemistry for their self-assembling properties and their ability to form supramolecular complexes with organic molecules and ions. Native calixarenes are achiral in essence but many examples of chemically modified chiral calix-arenes have been reported[77, 78]. Enantioselective recognition properties of these molecules have been demonstrated in solution. Nevertheless, only a few examples of chiral (surface) sensor based on calixarenes are reported. Guo et al. have described the synthesis of a dicyclopeptide bearing calixarenes [79]. These receptors have been synthesized by reacting 1,3-di(chlorocarbonylmethoxy)-ptert-butyl-calix[4]arene with serine containing cycloclopeptides (cf. Figure 10 ). They have been used to modify QCM sensor chips and their enantioselective binding properties evaluated with isomers of methyl-lactate. This calixarene based receptor possesses a higher affinity for the $\mathrm{R}$ enantiomer, and the autors conclude their paper pointing out the promising properties of this kind of stereoselective sensor. Surprisingly, to our knowledge, this is the only example of a calixarene-based stereoselective sensor. 

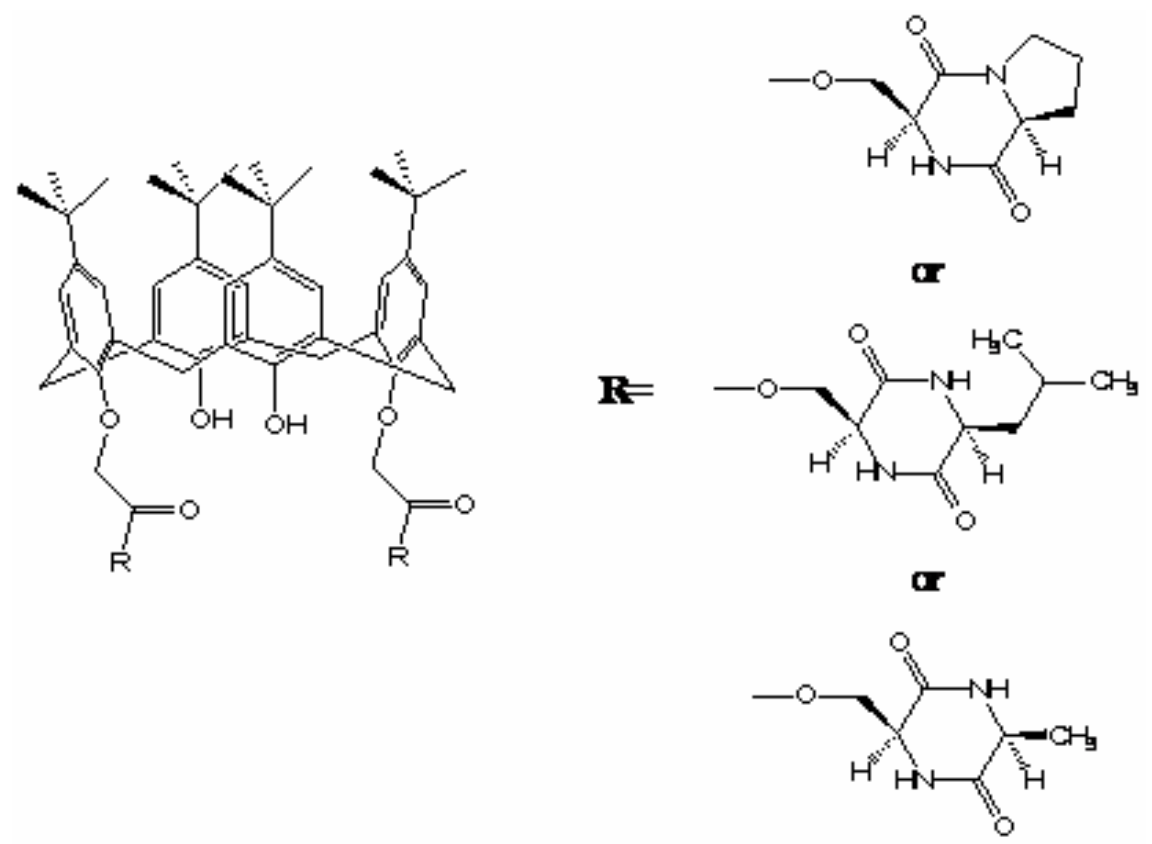

Figure 10. molecular formulae of cyclopeptides bearing calix[4]arenes.

Nevertheless, some examples of chiral recognition at interfaces using calix-arene based receptors have been reported. Liu et al. have designed amphiphilic calix-arene molecules bearing bi-cyclic guanidinium moieties. These molecules have been shown to self-assembe at the air-water interface to form stable Langmuir monolayers and are able to discriminate between D and L enantiomers of phenylalanine [80]. Nevertheless, these receptors have never been used to build durable chiral sensors. Some other examples of chiral recognition at interfaces have been reported for chiral calixresorcinarenes.

Calix-resorcinarenes are macrocyclic cone-shaped molecules, very similar in size and in shape to calix-arenes. They are produced via the acid catalyzed reaction of resorcinol and an aldehyde. Like calix-arenes, they have been widely studied by supramolecular chemists for their self-assembling and molecular recognition properties. Bilewicz and co-workers have designed several amphiphilic calixresorcinarenes, bearing chiral recognition moieties and have shown their stereoselective interactions with amino-acids at the air-water interface by mean of the Langmuir balance technique [81-83]. We have also developed an amphiphilic prolyl-bearing calix-resorcinarene and have shown that this receptor is able to discriminate between $\mathrm{D}$ and L-phenylalanine via the formation of a ternary complex with copper ions [84], a representation of the proposed interaction mechanism is presented in Figure 11.

\subsection{Crown-ethers}

Unlike calixarenes, some more examples of crown-ethers, used for enantioselective sensing have been published. Crown Ethers[85, 86] are cyclic polyethers discovered by Pedersen in early seventies[87]. Their widespread use in supramolecular chemistry could be attributed to their almost unlimited capabilities for forming host-guest complexes with ionic species. Many examples of chiral crown ethers are published but only a few reports on the use of these molecular receptors as sensitive sensor layer are available. 

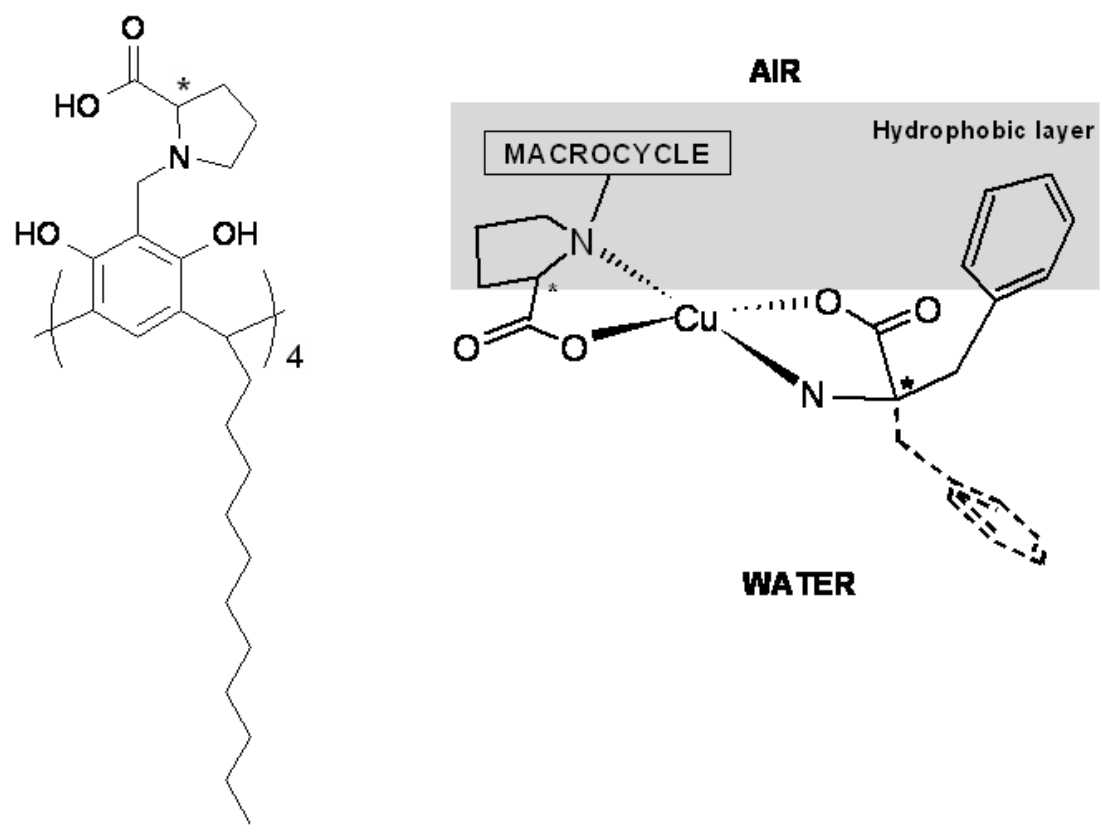

Figure 11. molecular formula and proposed mechanism for enantioselective recognition of phenylalanine using a chiral calix-resorcinarene at the air-water interface [reproduced with permission from Langmuir 2005, 21, 6503. Copyright 2005, the American Chemical Society].

To our knowleddge, the first report on the use of chiral crown-ethers for enantioselective sensing was published in 1980 [88]. In their pioneering work, Yasaka et al. demonstrated the enantioselectivity of four crown-ethers derivatives in plasticized PVC membranes with phenylalanine methyl ester and phenylethylamine.

Polymeric membrane electrodes based on the chiral crown ether, 2,3:4,5-bis-[1,2-(3phenylnaphtho)]-1,6,9,12,15,18-hexaoxacycloeicosa-2,4-diene were shown to be stereoselective for different amino acid methyl-esters, with the best value observed for phenylglycine methyl ester [89]. More recently, a crown-ether containing PVC plasticized membrane had been shown to have stereoselective complexation properties of 1-phenylethylammonium ions when incorporated into a plasticized PVC based electrode membrane, thus providing enantioselectivity. In addition to these sensing experiments, some crown-ether derivatives were studied for their enantioselective complexation properties at the air-water interface [90]. Badis et al. studied, at Langmuir monolayer surfaces, stereoselective interactions of four chiral amphiphilic crown ethers (cf. Figure 12) differing by the hydrophobic tail groups with amino-acids (alanine, valine, phenylglycine and tryptophane) [91]. Steroidal crown ether have also been studied at the air-water interface for their chiral recognition properties of methyl-ester amino-acids (alanine, valine, phenylalanine, tryptophan) [92]. 

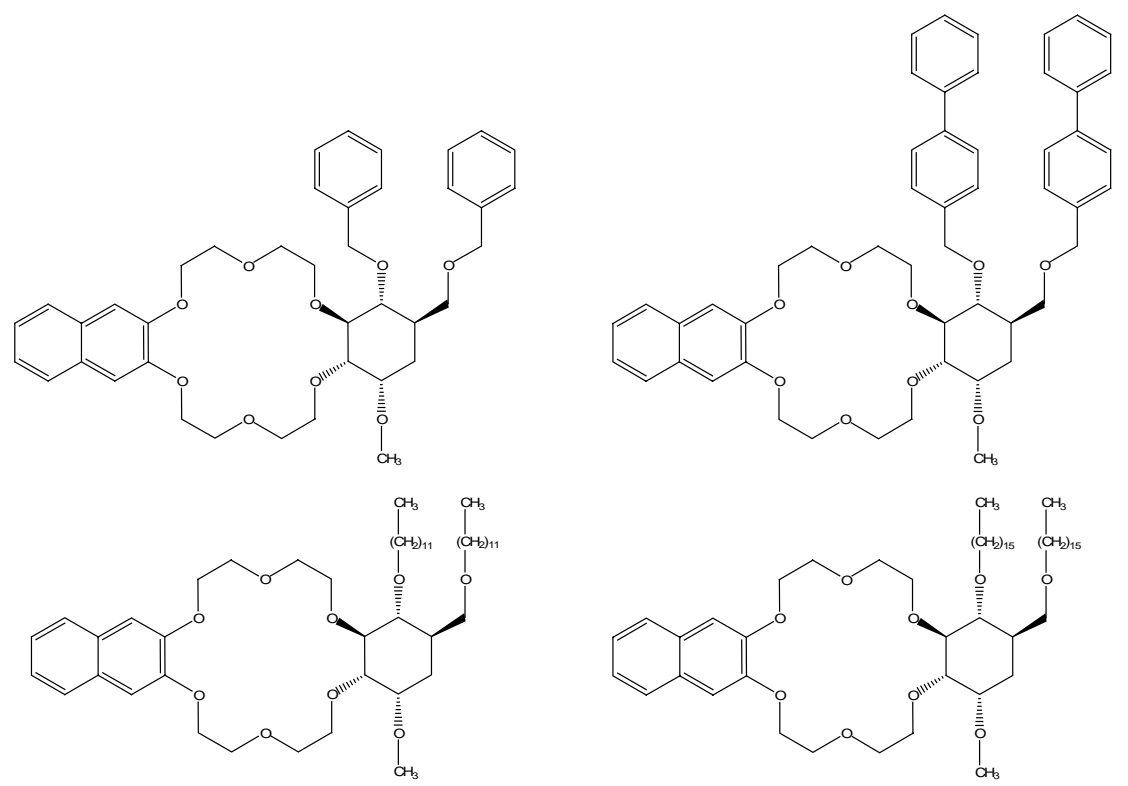

Figure 12. molecular formulas of four chiral crown-ethers, able of stereoselective molecular recognition at the air-water interface [reproduced with permission from Langmuir 2004, 20, 6259. Copyright 2005, the American Chemical Society].

\section{Concluding remarks}

In addition to their applications in chiral separation, cyclodextrins have been shown to be efficient receptors molecules for chiral sensing at interfaces. In this contribution we attempted to present an exhaustive list of achievements of cyclodextrin-based chiral sensors. Nevertheless, when comparing these results with the huge amount of papers published about chiral recognition in solution, we came to the conclusion that they are still not fully exploited for chiral sensing. In addition, it should be noted that even if a considerable body of work devoted to the design of calix-arene or crown-ether based chiral receptors was developed concurrently, their use in chiral sensing at interfaces is even more underexploited. In view of the scientific and industrial relevance of chiral sensors, we could expect that these research fields will receive increasing attention in the near future.

\section{References and Notes}

* “symmetry is boredom” [Victor Hugo, Les Misérables]

1. Buckingham, A. D.; Fowler, P. W.; Hutson, J. M. Theoretical studies of van der Waals molecules and intermolecular forces. Chem. Rev. 1988, 88, 963-88.

2. Brammer, L. Developments in inorganic crystal engineering. Chem. Soc. Rev. 2004, 33, 476-489.

3. Belkova, N. V.; Shubina, E. S.; Epstein, L. M. Diverse world of unconventional hydrogen bonds. Acc. Chem. Res. 2005, 38, 624-631.

4. Bushey, M. L.; Nguyen, T.-Q.; Zhang, W.; Horoszewski, D.; Nuckolls, C. Using hydrogen bonds to direct the Assembly of Crowded Aromatics. Angew. Chem., Int. Ed. 2004, 43, 5446-5453.

5. Desiraju, G. R. Hydrogen bridges in crystal engineering: interactions without borders. Acc. Chem. Res. 2002, 35, 565-573. 
6. Sherrington, D. C.; Taskinen, K. A. Self-assembly in synthetic macromolecular systems via multiple hydrogen bonding interactions. Chem. Soc. Rev. 2001, 30, 83-93.

7. Desiraju, G. R. The C-H $\cdots$ O Hydrogen bond: structural implications and supramolecular design. Acc. Chem. Res. 1996, 29, 441-449.

8. Eisenberg, D.; Kauzmann, W., The Structure and Properties of Water. Oxford University Press: Oxford, 2005.

9. Alvarez, S.; Palacios, A. A.; Aullon, G. Ligand orientation effects on metal-metal, ligand-ligand and metal-ligand interactions. Coord. Chem. Rev. 1999, 185-186, 431-450.

10. Cory, M. G.; Zerner, M. C. Metal-ligand exchange coupling in transition-metal complexes. Chem. Rev. 1991, 91, 813-822.

11. Ruchon, T.; Vallet, M.; Thepot, J.-Y.; Le Floch, A.; Boyd, R. W. Experimental evidence of magnetochiral interaction in Pasteur's tartrates. Comptes Rendus Physique 2004, 5, 273-277.

12. Reddy, I. K.; Mehvar, R., Chirality in Drug Design and Development. Marcel Dekker, Inc.: NewYork, 1994.

13. Cope, M. J. Understanding chirality: how molecules that are mirror images of each other can act differently in the Body. Anal. Proceed. 1993, 30, 498-500.

14. Wolf, C. Stereolabile Chiral compounds: analysis by dynamic chromatography and stopped-flow methods. Chem. Soc. Rev. 2005, 34, 595-608.

15. Roussel, C.; Del Rio, A.; Pierrot-Sanders, J.; Piras, P.; Vanthuyne, N. Chiral liquid chromatography contribution to the determination of the absolute configuration of enantiomers. $J$. Chromatography A 2004, 1037, 311-328.

16. Ward, T. J. Chiral separations. Anal. Chem. 2002, 74, 2863-2872.

17. Ward, T. J. Chiral separations. Anal. Chem. 2000, 72, 4521-4528.

18. vander Heyden, Y.; Mangelings, D.; Matthijs, N.; Perrin, C., Chiral Separations. 2005; Vol. 6, p 447-498.

19. Natishan, T. K. Recent progress in the analysis of pharmaceuticals by capillary electrophoresis. $J$. Liq. Chromatogr. Relat. Technol. 2005, 28, 1115-1160.

20. Laemmerhofer, M. Chiral separations by capillary electromigration techniques in nonaqueous media. II. enantioselective nonaqueous capillary electrochromatography. J. Chromatography, A 2005, 1068, 31-57.

21. Veuthey, J.-L. Capillary electrophoresis in pharmaceutical and biomedical analysis. Anal. Bioanal. Chem. 2005, 381, 93-95.

22. Guebitz, G.; Schmid, M. G. Recent advances in chiral separation principles in capillary electrophoresis and capillary electrochromatography. Electrophoresis 2004, 25, 3981-3996.

23. Ward, T. J.; Hamburg, D.-M. Chiral separations. Anal. Chem. 2004, 76, 4635-4644.

24. Riekkola, M.-L.; Siren, H. Chiral separation by capillary electrophoresis in nonaqueous medium. Methods Mol Biol. 2004, 243, 365-373.

25. Schurig, V. Practice and theory of enantioselective complexation gas chromatography. $J$. Chromatography A 2002, 965, 315-356. 
26. Eiceman, G. A.; Hill, H. H., Jr.; Gardea-Torresdey, J. Gas chromatography. Anal. Chem. 1998, 70, 321R-339R.

27. Schurig, V. Enantiomer separation by gas chromatography on chiral stationary phases. $J$. Chromatography A 1994, 666, 111-29.

28. Kasper, M.; Busche, S.; Gauglitz, G., in Frontiers in Chemical Sensors, Novel Principles and Techniques; Orellana, G.; Moreno-Bondi, M. C., Eds; Springer-Verlag: Berlin, 2005; Vol. 3, p 323-341.

29. Hillberg, A. L.; Brain, K. R.; Allender, C. J. Molecular imprinted polymer sensors: implications for therapeutics. Adv. Drug Deliv. Rev. 2005, 57, 1875-1889.

30. Mahony, J. O.; Nolan, K.; Smyth, M. R.; Mizaikoff, B. Molecularly imprinted polymers-potential and challenges in analytical chemistry. Anal. Chim. Acta 2005, 534, 31-39.

31. Zhang, X. X.; Bradshaw, J. S.; Izatt, R. M. Enantiomeric recognition of amine compounds by chiral macrocyclic receptors. Chem. Rev. 1997, 97, 3313-3361.

32. Szejtli, J. Introduction and general overview of cyclodextrin chemistry. Chem. Rev. 1998, 98, 1743-1754.

33. Szejtli, J. Past, present, and future of cyclodextrin Research. Pure Appl. Chem. 2004, 76, 18251845.

34. Szejtli, J., in Encyclopedia of Nanoscience and Nanotechnology; Marcel Dekker: New York, 2004; Vol. 2, p 283-304.

35. Villiers, A. Sur la transformation de la fécule en dextrine par le ferment butyrique. Compt. Rend. Fr. Acad. Sci. 1891, 112, 435-438.

36. Freudenberg, K.; G., B.; Ewald, L.; Soff, K. Hydrolysis and acetolysis of starch and of the Schardinger dextrins. Ber. Deutsch. Chem. Ges. 1936, 69, 1258.

37. Khan, A. R.; Forgo, P.; Stine, K. J.; D'Souza, V. T. Methods for selective modifications of cyclodextrins. Chem. Rev. 1998, 98, 1977-1996.

38. Connors, K. A. The stability of cyclodextrin complexes in solution. Chem. Rev. 1997, 97, 13251357.

39. Schneider, H.-J.; Hacket, F.; Ruediger, V.; Ikeda, H. NMR studies of cyclodextrins and cyclodextrin complexes. Chem. Rev. 1998, 98, 1755-1785.

40. Szejtli, J. Utilization of cyclodextrins in industrial products and processes. J. Mater. Chem. 1997, 7, 575-587.

41. Cramer, F.; Dietsche, W. Occlusion compounds. XV. Resolution of racemates with cyclodextrins. Chem. Ber. 1959, 92, 378-84.

42. Kano, K.; Nishiyabu, R., General mechanism for chiral recognition by native and modified cyclodextrins J. Incl. Phenom. Macrocyclic Chem. 2002, 44, 355-359

43. Kano, K. Mechanisms for chiral recognition by cyclodextrins. J. Phys. Org. Chem. 1997, 10, 286291.

44. Easton, C. J.; Lincoln, S. F. Chiral discrimination by modified cyclodextrins. Chem. Soc. Rev. 1996, 25, 163-170. 
45. Ogston, A. G. Interpretation of experiments on metabolic processes, using isotopic tracer elements. Nature 1948, 162, 963.

46. Behr, J.-P., The Lock and Key Principle. The State of the Art-100 Years on. Wiley: Chichester, 1994; Vol. 1.

47. Kataky, R.; Bates, P. S.; Parker, D. Functionalized alpha-cyclodextrins as potentiometric chiral sensors. Analyst 1992, 117, 1313-1317.

48. Bates, P. S.; Kataky, R.; Parker, D. A chiral sensor based on a peroctylated alpha-Cyclodextrin. J. Chem. Soc., Chem. Commun. 1992, 153-155.

49. Bates, P. S.; Kataky, R.; Parker, D. Chiral sensors based on lipophilic cyclodextrins: interrogation of enantioselectivity by combined NMR, structural correlation and electrode response studies. $J$. Chem. Soc., Perkin Trans. 2 1994, 669-75.

50. Kataky, R.; Parker, D.; Kelly, P. M. Potentiometric, enantioselective sensors for alkyl and aryl ammonium-ions of pharmaceutical significance, based on lipophilic cyclodextrins. Scand. J. Clinical Lab. Invest. 1995, 55, 409-419.

51. Stefan, R. I.; van Staden, J. F.; Baiulescu, G. E.; Aboul-Enein, H. Y. A potentiometric, enantioselective membrane electrode for S-ramipril assay. Chem. Anal. 1999, 44, 417-422.

52. Stefan, R.-I.; Van Staden, J. F.; Aboul-Enein, H. Y. Detection of S-enantiomers of cilazapril, pentopril, and trandolapril using a potentiometric, enantioselective membrane electrode. Electroanalysis 1999, 11, 192-194.

53. Ozoemena, K. I.; Stefan, R.-I.; van Staden, J. F.; Aboul-Enein, H. Y. Enantioanalysis of Sperindopril using different cyclodextrin-based potentiometric sensors. Sens. Actuators, B 2005, B105, 425-429.

54. Stefan, R.-I.; Van Staden, J. F.; Aboul-Enein, H. Y. S-Perindopril assay using a potentiometric, enantioselective membrane electrode. Chirality 1999, 11, 631-634.

55. Stefan, R. I.; Van Staden, J. F.; Aboul-Enein, H. Y. A new construction for potentiometric, enantioselective membrane electrodes, and use for L-proline assay. Anal. Lett. 1998, 31, 17871794.

56. Shahgaldian, P.; Hegner, M.; Pieles, U. A cyclodextrin self-assembled monolayer (SAM) based surface plasmon resonance (SPR) Sensor for Enantioselective Analysis of Thyroxine. J. Inclusion Phenom. Macrocyclic Chem. 2005, 53, 35-39.

57. *Maeda, Y.; Fukuda, T.; Yamamoto, H.; Kitano, H. Regio- and stereoselective complexation by a self-assembled monolayer of thiolated cyclodextrin on a gold electrode. Langmuir 1997, 13, 4187-4189.

58. *Fukuda, T.; Maeda, Y.; Kitano, H. Stereoselective inclusion of DOPA derivatives by a selfassembled monolayer of thiolated cyclodextrin on a gold electrode. Langmuir 1999, 15, 18871890.

59. Stefan, R.-I.; Van Staden, J. F.; Aboul-Enein, H. Y. A new construction for a potentiometric, enantioselective membrane electrode-its utilization to the S-Captopril Assay. Talanta 1999, 48, 1139-1143.

60. Ozoemena, K. I.; Stefan, R.-I. Enantioselective potentiometric membrane electrodes based on $\alpha$-, $\beta$ - and $\gamma$-cyclodextrins as chiral selectors for the assay of L-proline. Talanta 2005, 66, 501-504. 
61. Beulen, M. W. J.; Bugler, J.; De Jong, M. R.; Lammerink, B.; Huskens, J.; Schonherr, H.; Vancso, G. J.; Boukamp, B. A.; Wieder, H.; Offenhauser, A.; Knoll, W.; Van Veggel, F. C. J. M.; Reinhoudt, D. N. Host-guest interactions at self-assembled monolayers of cyclodextrins on gold. Chem. Eur. J. 2000, 6, 1176-1183.

62. Auletta, T.; Dordi, B.; Mulder, A.; Sartori, A.; Onclin, S.; Bruinink, C. M.; Peter, M.; Nijhuis, C. A.; Beijleveld, H.; Schoenherr, H.; Vansco, G. J.; Casnati, A.; Ungaro, R.; Ravoo, B. J.; Huskens, J.; Reinhoudt, D. N. Writing patterns of molecules on molecular printboards. Angew. Chem., Int. Ed. 2004, 43, 369-373.

63. Yamamoto, H.; Maeda, Y.; Kitano, H. Molecular recognition by self-assembled monolayers of cyclodextrin on Ag. J. Phys. Chem. B 1997, 101, 6855-6860.

64. Schalley, C. A. Molecular recognition and supramolecular chemistry in the gas phase. Mass Spec. Rev. 2002, 20, 253-309.

65. Ide, J.; Nakamoto, T.; Moriizumi, T. Discrimination of aromatic optical isomers using quartzresonator sensors. Sens. Actuators, A 1995, 49, 73-78.

66. Fietzek, C.; Hermle, T.; Rosenstiel, W.; Schurig, V. Chiral discrimination of limonene by use of beta-cyclodextrin-coated quartz-crystal-microbalances (QCMs) and data evaluation by artificial neuronal networks. Fresenius J. Anal. Chem. 2001, 371, 58-63.

67. May, L. P.; Byfield, M. P.; Lindstrom, M.; Wunsche, L. F. Chiral discrimination using a quartz crystal microbalance and comparison with gas chromatographic retention data. Chirality 1997, 9, 225-232.

68. Ng, S. C.; Sun, T.; Chan, H. S. O. Chiral discrimination of enantiomers with a self-assembled monolayer of functionalized beta-cyclodextrins on Au surfaces. Tetrahedron Lett. 2002, 43, 28632866.

69. Ng, S. C.; Sun, T.; Chan, H. S. O. Durable chiral sensor based on quartz crystal microbalance using self-assembled monolayer of permethylated beta-cyclodextrin. Macromol. Symp. 2003, 192, 171-181.

70. Hierlemann, A.; Ricco, A. J.; Bodenhofer, K.; Gopel, W. Effective use of molecular recognition in gas sensing: results from acoustic wave and in situ FT-IR measurements. Anal. Chem. 1999, 71, 3022-3035.

71. Kieser, B.; Fietzek, C.; Schmidt, R.; Belge, G.; Weimar, U.; Schurig, V.; Gauglitz, G. Use of a modified cyclodextrin host for the enantioselective detection of a halogenated diether as chiral guest via optical and electrical transducers. Anal. Chem. 2002, 74, 3005-3012.

72. Bodenhofer, K.; Hierlemann, A.; Juza, N.; Schurig, V.; Gopel, W. Chiral discrimination of inhalation anesthetics and methyl propionates by thickness shear mode resonators: new insights into the mechanisms of enantioselectivity by cyclodextrins. Anal. Chem. 1997, 69, 4017-4031.

73. Sallas, F.; Kovacs, J.; Pinter, I.; Jicsinszky, L.; Marsura, A. One-step synthesis of new urea-linked b-cyclodextrin dimers. Tetrahedron Letters 1996, 37, 4011-4014.

74. Arduini, A.; Casnati, A. In Macrocycle Synthesis; Parker, D., Ed.; Oxford University Press: Oxford, 1996; pp 145-173.

75. Atwood, J. L.; Steed, J. W., Encyclopedia of Supramolecular Chemistry. Marcel Dekker: New York, 2004. 
76. Gutsche, C. D., Calixarenes Revisited. The Royal Society of Chemistry: Letchworth, 1998; p 233 pp.

77. Diamond, D.; Nolan, K. Calixarenes: designer ligands for chemical sensors. Anal. Chem. 2001, 73, 22A-29A.

78. Vysotsky, M.; Schmidt, C.; Bohmer, V. Chirality in Calixarenes and Calixarene Assemblies. Advances in Supramolecular Chemistry 2000, 7, 139-233.

79. Guo, W.; Wang, J.; Wang, C.; He, J. Q.; He, X. W.; Cheng, J. P. Design, synthesis, and enantiomeric recognition of dicyclodipeptide-bearing Calix[4]arenes: a promising family for chiral gas sensor coatings. Tetrahedron Lett. 2002, 43, 5665-5667.

80. Liu, Y.; You, C. C.; Kang, S. Z.; Wang, C.; Chen, F.; He, X. W. Synthesis of novel betacyclodextrin and calixarene derivatives and their use in gas sensing on the basis of molecular recognition. Eur. J. Org. Chem. 2002, 607-613.

81. Pietraszkiewicz, M.; Prus, P.; Bilewicz, R. pH dependent enantiomeric recognition of amino acids by Mannich-type calix[4]resorcinarenes in Langmuir monolayers. Polish J. Chem. 1999, 73, 1845-1853.

82. Prus, P.; Pietraszkiewicz, M.; Bilewicz, R. Monolayers of chiral calix[4]resorcinarenes. surface pressure and surface Potential Studies. Supramol. Chem. 1998, 10, 17-25.

83. Pietraszkiewicz, M.; Prus, P.; Bilewicz, R. pH dependent enantioselection of amino acids by phosphorous-containing calix[4]resorcinarene in Langmuir monolayers. Polish J. Chem. 1999, 73, 2035-2042.

84. Shahgaldian, P.; Pieles, U.; Hegner, M. Enantioselective reognition of phenylalanine by a chiral amphiphilic macrocycle at the air-water interface: a copper-mediated mechanism. Langmuir 2005, 21, 6503-6507.

85. Gokel, G. W.; Leevy, W. M.; Weber, M. E. Crown ethers: sensors for ions and molecular scaffolds for materials and biological models. Chem. Rev. 2004, 104, 2723-2750.

86. Bradshaw, J. M.; Izatt, R. M.; Bordunov, A. V.; Zhu, C. Y.; Hathaway, J. K.; in Comprehensive Supramolecular Chemistry, Gokel, G. W.; Ed; Pergamon: Oxford, 1996; Vol. 1, p 35

87. Pedersen, C. J. The discovery of crown ethers. Science 1988, 241, 536-540.

88. Yasaka, Y.; Yamamoto, T.; Kimura, K.; Shono, T. Simple evaluation of enantiomer selectivity of crown ether using a membrane electrode. Chem. Lett. 1980, 769-72.

89. Shinbo, T.; Yamaguchi, T.; Nishimura, K.; Kikkawa, M.; Sugiura, M. Enantiomer-selective membrane electrode for amino acid methyl esters. Anal. Chim. Acta 1987, 193, 367-71.

90. Badis, M.; Tomaszkiewicz, I.; Joly, J.-P.; Rogalska, E. Enantiomeric recognition of amino acids by amphiphilic crown ethers in Langmuir monolayers. Langmuir 2004, 20, 6259-6267.

91. Horvath, V.; Takacs, T.; Horvai, G.; Huszthy, P.; Bradshaw, J. S.; Izatt, R. M. Enantiomer selectivity of ion-selective electrodes based on a chiral crown-ether ionophore. Anal. Lett. 1997, 30, 1591-1609.

92. Kawabata, H.; Shinkai, S. Chiral recognition of $\alpha$-amino acid derivatives by a steroidal crown Ether at the air-water interface. Chem. Lett. 1994, 375-378.

(C) 2006 by MDPI (http://www.mdpi.org). Reproduction is permitted for noncommercial purposes. 